\title{
A Study of the Effects of Metformin, a Biguanide Derivative, on Annulus Fibrosus and Nucleus Pulposus Cells
}

\author{
Yasin Emre KAYA ${ }^{1}$, Numan KARAARSLAN², Ibrahim YILMAZ3, Duygu YASAR SIRIN ${ }^{4}$, Hande AKALAN ${ }^{4}$, \\ Hanefi OZBEK ${ }^{3}$ \\ ${ }^{1}$ Abant Izzet Basal University School of Medicine, Department of Orthopaedics and Traumatology, Bolu, Turkey \\ ${ }^{2}$ Namik Kemal University, School of Medicine, Department of Neurosurgery, Tekirdag, Turkey \\ ${ }^{3}$ Istanbul Medipol University School of Medicine, Department of Medical Pharmacology, Istanbul, Turkey \\ ${ }^{4}$ Namik Kemal University, Faculty of Arts and Sciences, Department of Molecular Biology and Genetics, Tekirdag, Turkey
}

Corresponding author: Numan KARAARSLAN numikara@yahoo.com

\section{ABSTRACT}

AIM: To investigate the effects of metformin, a drug used widely for the treatment of type 2 diabetes mellitus, on human primary cell cultures prepared from uninjured segment of disc material intervertebral disk tissues.

MATERIAL and METHODS: Primary cell cultures were prepared using the tissues of six patients (three males and three females) who had undergone lumbar microdiscectomy and sequestrectomy. Untreated samples served as the control group, and metformintreated samples served as the experimental group. All the samples were evaluated using an inverted light microscope, acridine orange/propidium iodide staining (AO/PI), and a fluorescence microscope. The cytostatic and cytotoxic effects of metformin, which was administered to the samples using a commercial MTT assay kit, were also evaluated. The data obtained were statistically assessed, and the alpha significance value was accepted as less than 0.05 . In addition, for the groups' changes in the expressions of chondroadherin (CHAD), cartilage oligomeric matrix protein (COMP), interleukin-1 $\beta$ (IL-1 $\beta$ ) matrix metalloproteinase 7 (MMP-7), and matrix metalloproteinase 19 (MMP-19), genes related to the extracellular matrix synthesis and degradation were determined using gene-specific TaqMan Gene Expression Assays.

RESULTS: The administration of the drug adversely affected nucleus pulposus (NP)/annulus fibrosus (AF) cells and extracellular matrix-like structures. This was statistically significant $(p<0.05)$.

CONCLUSION: Clinicians should not disregard the adverse effects of metformin, which is used widely in clinical practice, on the components of intervertebral disk tissues.

KEYWORDS: Annulus fibrosus, Intervertebral disc tissue, Metformin, Nucleus pulposus, Primary human cell culture

\section{INTRODUCTION}

M etformin, a biguanide derivative, is commonly used for the treatment of type 2 diabetes mellitus, demonstrating its antihyperglycemic effect by improving cellular insulin sensitivity. Even with the administration of a high dose, metformin does not result in hypoglycemia (19). Metformin also decreases triglyceride levels and has slightly beneficial effects on total and high-density lipoprotein cholesterol levels $(10,21)$.

Some reports have suggested that metformin is effective for lifespan extension (22), and can be used for the treatment of frailty syndrome (8), and even Behçet's disease (30) since it reduces inflammation. As observed with many drugs, however, metformin also has serious side effects-including
Yasin Emre KAYA

(10) : 0000-0002-5412-8355

Numan KARAARSLAN (1) : 0000-0001-5590-0637

Ibrahim YILMAZ (D) : 0000-0003-2003-6337
Duygu YASAR SIRIN (1) : 0000-0002-1224-442X

Hande AKALAN : : 0000-0002-5922-2498

Hanefi OZBEK (D) : 0000-0002-8084-7855 
muscle weakness, slow heart rate, dizziness, fainting, and shortness of breath, stomach pain, increased insomnia, chills, and muscle pain. It can also disrupt the composition of the intestinal microbiota in normoglycemic adults (2), and lead to lactic acidosis $(23,29)$.

Metformin is absorbed through the gastrointestinal tract, does not markedly bind to plasma proteins and reaches a steady-state concentration within 24 hours (h) to 48 h. It widely permeates all tissues, and its oral bioavailability ranges from $50 \%$ to $60 \%$. Some studies have reported that the mean elimination half-life of metformin is about $3.5 \mathrm{~h}$, and $90 \%$ of metformin is excreted unchanged-mainly in the urine, without undergoing liver metabolism (enterohepatic circulation-firstpass effect) $(4,6)$.

Metformin is commonly used to treat intervertebral disk degeneration since it prevents, decelerates, and reverses the degeneration process. It is also known to reduce nucleus pulposus (NP) cell aging and apoptosis $(3,19)$.

The aim of this present study was to investigate the effects of metformin on human primary cell cultures isolated from intervertebral disk tissues. Metformin was administered to these cultures for $24 \mathrm{~h}, 48 \mathrm{~h}$, and $72 \mathrm{~h}$. The viability and proliferation of annulus fibrosus (AF)/NP cells and the toxicity of metformin were analyzed in vitro. In addition, the gene expression levels of chondroadherin (CHAD), cartilage oligomeric matrix protein (COMP), matrix metalloproteinase 7 (MMP-7), and matrix metalloproteinase 19 (MMP-19), as well as interleukin-1 $\beta$ (IL-1 $1 \beta$ ), were examined using reverse transcription-quantitative polymerase chain reaction (RTqPCR) analysis.

\section{MATERIAL and METHODS}

Analyses were performed by the same researchers and repeated at least three times to minimize experimental errors. The researchers were blinded to the dosages and drugs - that is, the components in the culture medium.

Patients with diabetic ketoacidosis, acute or chronic metabolic acidosis, renal dysfunction (creatinine > $1.2 \mathrm{mg} / \mathrm{dL}$ ) were excluded. Patients with congestive heart failure, chronic liver diseases, and recent myocardial infarction who had received medication were also excluded. In addition, patients with conditions that may cause lactic acidosis-such as acute or chronic alcoholism, hypoxemia, shock, or respiratory failurewere excluded.

The tissues of six patients, of whom three were males and three were females, were used to prepare human primary cultures. The ages of patients whose tissues were used varied from 18 to 38 years, with a mean patient age of $31 \pm 3.67$ years. The patients had undergone lumbar microdiscectomy and sequestrectomy due to lumbar disk herniation. Following the resection of intervertebral disk tissues, the tissues were placed in sterile containers containing penicillin-streptomycin and transferred to the laboratory at $4^{\circ} \mathrm{C}$. The cell cultures were prepared according to the protocol described by Karaarslan et al. (13-17).
The tissue samples were irrigated with $0.9 \%$ isotonic sodium chloride solution in a laminar flow cabinet (Air FlowNUVE/NF-800 R, Ankara, Turkey) and washed three times consecutively with a buffered saline solution to remove the red blood cells. The resulting mechanically degraded tissues were then transferred to Falcon tubes. A $0.375 \mathrm{mg}$ sample of Clostridium histolyticum collagenase type II enzyme (Cat\#1148090, Sigma-Aldrich, Germany), dissolved in Hank's Balanced Salt Solution HBSS-1X, 14060-040, Gibco), was added to the tissue samples, and the tissue samples were incubated overnight in an incubator (NUVE, 06750, Ankara, Turkey) with $5 \% \mathrm{CO}_{2}$ at $37^{\circ} \mathrm{C}$. The medium in the Falcon tubes was centrifuged three times consecutively at 1100 rpm. The supernatants were then taken out, and the obtained cell pellets were resuspended in a cell culture medium (Dulbecco's Modified Eagle Medium [Cat\#42430025; Thermo Fisher Scientific, Waltham, MA, USA] supplemented with 1\% penicillin-streptomycin [Cat\#15140122; Thermo Fisher Scientific, USA] and 5\% fetal bovine serum [Cat\#16000044; Thermo Fisher Scientific, USA]).

The cells were stained with trypan blue and counted under an inverted light microscope at $10 \times$ magnification. The counted cells were plated in several well plates for analyses. Later, they were plated with the following specifications: $5 \times 10^{4}$ cells per well in 96 well plates for MTT and acridine orange (AO)/ propidium iodide $(\mathrm{Pl})$ analyses and $5 \times 10^{6}$ cells per dish in petri dishes $(100 \mathrm{~mm})$ for inverted light microscopy assays. After incubating the plates and the petri dishes overnight, metformin was added so as to perform experiments on the cell cultures that became confluent and adhered to the cell culture plates or dishes.

\section{Administration of metformin to the cell cultures}

A 1000 mg metformin tablet (Diaformin ${ }^{\circledR} 1000$ mg film tablet, Ali Raif Pharmaceuticals Inc., Istanbul, Turkey) was dissolved in Dulbecco's Modified Eagle Medium-containing 5\% dimethyl sulfoxide, as previously described-to obtain a 10 $\mathrm{mg} / \mathrm{ml}$ stock solution. The stock solution was diluted to attain a final concentration of $20 \mu \mathrm{g} / \mathrm{ml}$ and then added to the cell cultures. The samples without drug treatment served as the control group. Analyses were performed at 24, 48, and 72 hours for the control group and metformin-treated samples.

\section{Analyses}

Using an inverted light microscope, cell surface morphology and viability were examined under $4 \times, 10 x, 20 x$, and $40 x$ magnifications. Analyses were performed at $0,24 \mathrm{~h}, 48 \mathrm{~h}$ and $72 \mathrm{~h}$. Membrane permeability assays were performed using fluorescence microscopy. The results of the assays were confirmed using the nucleic acid binding dyes $\mathrm{AO}$ and $\mathrm{PI}$. The viable cells generated green fluorescence, and by contrast, the apoptotic or dead cells with poor membrane integrity generated red fluorescence $(14,15,17)$.

A commercial MTT kit (3 [4,5-dimethylthiazol-2-yl] 2,5-diphenyltetrazolium bromide [Vybrant MTT Cell Proliferation Assay, Cat \#V13154, Thermo Fisher Scientific, USA]), based on the principle that formazan crystals generate thiazole and a blue coloration, was used to analyze proliferation. This method 
is predicated on the measurement of color changes, which occur via formazan (purple) production as cells undergo proliferation using tetrazolium through increasing dehydrogenase enzyme activity by spectrophotometry as absorbance. MTT assays were performed at a wavelength of $570 \mathrm{~nm}$, and the control cell viability was taken as $100 \%$. The proliferation and the inhibition of the proliferation were calculated using the following formulas: "Test optical density (OD) / Control ODX100" and "1- Test OD / Control OD," respectively, and the data were recorded for statistical analysis $(13-18,25)$.

The statistical analyses were performed using Minitab (version 18.0) software. The data were evaluated with a confidence interval of $95 \%$. The results were presented as mean \pm standard deviation. An analysis of variance test was performed to test for significant differences across the groups' means. When differences across groups were observed, Tukey's honestly significant difference post hoc test was used for multiple pairwise comparisons. The alpha significance value was accepted as less than 0.05 .

Real-time PCR analysis of CHAD, COMP, MMP-7, MMP-19 and IL-1 $\beta$ expressions.

Total RNA was extracted from cultured primary AF/NP cells using the PureLink ${ }^{T M}$ RNA Mini Kit. A total of 50 ng of RNA was reverse-transcribed using a high capacity cDNA RT kit to obtain cDNA (1). To determine gene expression profiles, all genes were amplified using TaqMan Gene Expression Assays for CHAD, $\beta$-actin (ACT $\beta$ ), COMP, MMP-7, MMP-19, and IL1 $\beta$. qPCR analysis was performed on an Applied Biosystems 7300/7500 real-time PCR system (Thermo Fisher Scientific, USA) with a reaction mixture consisting of $1 \mu \mathrm{l}$ TaqMan Gene Expression Master Mix, $10 \mu \mathrm{l}$ TaqMan Gene Expression Master Mix, $4 \mu \mathrm{l}$ cDNA template, and UltraPure Dnase/Rnase free distilled water for each gene in MicroAmp Fast Optical 96-Well Reaction Plates under the following thermocycling conditions: $2 \mathrm{~min}$ at $50^{\circ} \mathrm{C}, 10 \mathrm{~min}$ at $95^{\circ} \mathrm{C}, 15 \mathrm{sec}$ at $95^{\circ} \mathrm{C}$ and $1 \mathrm{~min}$ at $60^{\circ} \mathrm{C}$ for 40 cycles for each duration (1). As a result of the qPCR experiment, the relative quantity values of each sample were obtained using the 7500 Fast SDS program V.2.3 (Thermo Fisher Scientific, USA). ACT $\beta$ was used as an endogenous control to normalize the targeted gene expressions (1). For obtaining comparative results, a reference sample (Group 1, $0 \mathrm{~h}$ ) was used, and relative quantity values were calculated using the $2^{-\triangle \Delta C a}$ method.

\section{Ethics Approval and Consent to Participate}

The present research was approved by the Local Ethics Com- mittee of Istanbul Medipol University, Faculty of Medicine (no. 29.11.2017- 10840098/604.01.01/E.44192). Written consent forms were also obtained from the patients whose tissues were used in the study.

\section{Human and Animal Rights}

No animals were used in the study all reported human were experimented in accordance with the ethical standards of the committee responsible for human experimentation (institutional and national), and with the Helsinki Declaration of 1975, as revised in 2008 (http://www.wma.net/en/20activities/10ethics/10helsinki/).

\section{Consent for Publication}

Written consent forms were obtained from all the patients undergoing surgery whose tissues were used in the preparation of the primary cell cultures.

\section{RESULTS}

The spectrophotometric results were consistent with the microscopic images. A decrease in the percentage of confluency in the metformin-treated group was observed. The extracellular matrix structures in the metformin-treated group were disrupted when compared to the control group (Figure 1).

The administration of metformin significantly decreased proliferation at $72 \mathrm{~h}$ when compared to the control group $(p<0.05)$ (Table I and Figure 2). The proliferation continued in the untreated group at $72 \mathrm{~h}$. In the metformin-treated group, the proliferation suppressed at $72 \mathrm{~h}$ when compared to the control group.

Changes in the expressions of CHAD, COMP, IL-1b, MMP-7, and MMP-19 were statistically significant in the metformintreated group (Table II and Figure 3). Expression for all genes was normalized with internal control ACTb of the same sample. In all experimental groups, changes in gene expression were indicated as a fold after comparing them with the reference sample ( untreated AF/NPC culture samples at $0 \mathrm{~h}$ ). CHAD expression (0.71-fold) remained unchanged in the control group. It ceased at $48 \mathrm{~h}$ and was eliminated at $72 \mathrm{~h}$ in the metformin-treated group. COMP expression (0.62-fold) increased 9.17 -fold at $48 \mathrm{~h}$ but decreased 0.29 -fold at $72 \mathrm{~h}$ in the control group. It decreased 0.52 -fold following metformin treatment. IL- $1 \mathrm{~b}$ expression $(0.75$-fold) increased 3.80 -fold at $72 \mathrm{~h}$ in the control group, whereas it decreased 1 -fold at 24 $\mathrm{h}$ and was eliminated at $48 \mathrm{~h}$ after metformin treatment. The

Table I: The Relationship Between Incubation Period and Proliferation in the Metformin-Treated Samples

\begin{tabular}{lcccc}
\hline Source & Adj SS & Adj MS & F-Value & $\mathbf{p}^{*}$ \\
\hline Application & 0.040903 & 0.040903 & 171622.50 & $\mathbf{0 . 0 0 0}$ \\
\hline Time & 0.362598 & 0.120866 & 507130.08 & $\mathbf{0 . 0 0 0}$ \\
\hline Application* Time & 0.061991 & 0.020664 & 86700.66 & $\mathbf{0 . 0 0 0}$ \\
\hline
\end{tabular}

DF: Degrees of freedom, Adj SS: Adjusted sum of squares, Adj MS: Adjusted mean square, *: An analysis of variance test (ANOVA, $p<0.05)$. 


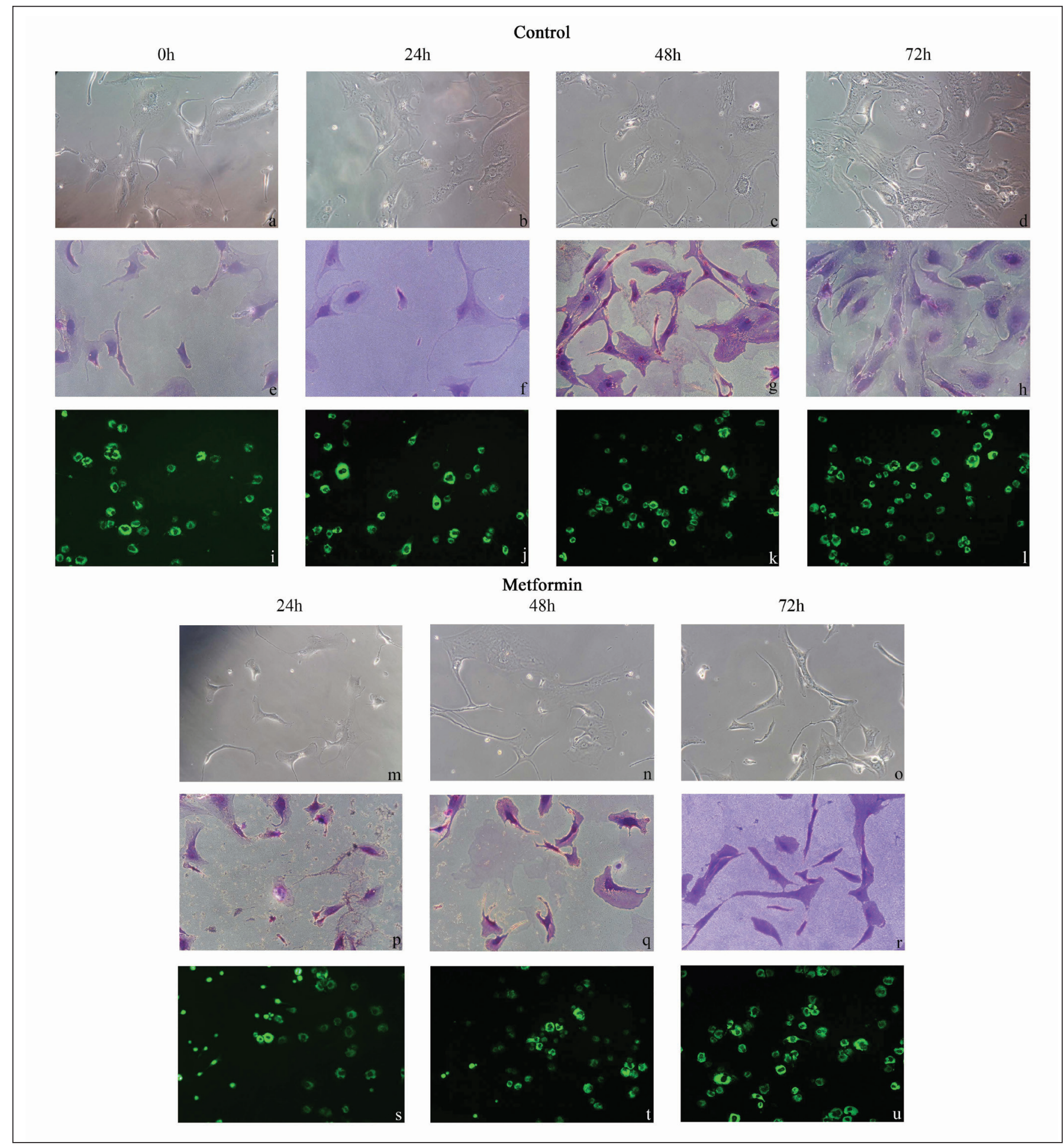

Figure 1: Inverted microscopy of nucleus pulposus and annulus fibrosus cell cultures. "a" to "I" represent control group cultures, and "m" to "u" represent metformin-treated cultures. "a," "b," "c," and "d" are micrographs of control group cells after first passage incubated for 0 hour, 24 hours, 48 hours, and 72 hours, respectively, under $20 \times$ magnification. "c," "ff," "g," and "h" are micrographs of the same culture but stained with Giemsa stain. "i,," "j,," "k," and "l”" are micrographs of acridine orange/propidium iodide-stained control group cells after first passage incubated for 0 h, 24 h, 48 h, and 72 h, respectively, under 10x magnification. "m," "n," and "o" are micrographs of metformin-treated group cells after first passage incubated for 24 hours, 48 hours, and 72 hours, respectively, under $20 \times$ magnification. "p," "q," and "r" are micrographs of the same culture but stained with Giemsa stain. "s," "t," and "u" acridine orange/ propidium iodide-stained metformin-treated group cells after first passage incubated for 24 hours, 48 hours, and 72 hours, respectively, under $10 \times$ magnification. 
Kaya YE. et al: Cytotoxicity of Metformin on Intervertebral Disc

Table II: The Relationship Between Incubation Period and Gene Expression in the Metformin-Treated Samples

\begin{tabular}{lcccc}
\hline Source & Adj SS & Adj MS & F-Value & $\mathbf{p}^{*}$ \\
\hline Application & 186.36 & 186.363 & 235754.39 & $\mathbf{0 . 0 0 0}$ \\
\hline Time & 174.05 & 87.025 & 110088.78 & $\mathbf{0 . 0 0 0}$ \\
\hline Marker & 196.80 & 49.201 & 62240.90 & $\mathbf{0 . 0 0 0}$ \\
\hline Application*Time & 244.72 & 122.360 & 154788.74 & $\mathbf{0 . 0 0 0}$ \\
\hline Application*Marker & 178.67 & 44.669 & 56506.99 & $\mathbf{0 . 0 0 0}$ \\
\hline Time*Marker & 479.62 & 59.953 & 75841.61 & $\mathbf{0 . 0 0 0}$ \\
\hline Application*Time*Marker & 480.58 & 60.072 & 75993.25 & $\mathbf{0 . 0 0 0}$
\end{tabular}

Adj SS: Adjusted sum of squares, Adj MS: Adjusted mean square, *, an analysis of variance test (ANOVA, $p<0.05)$.

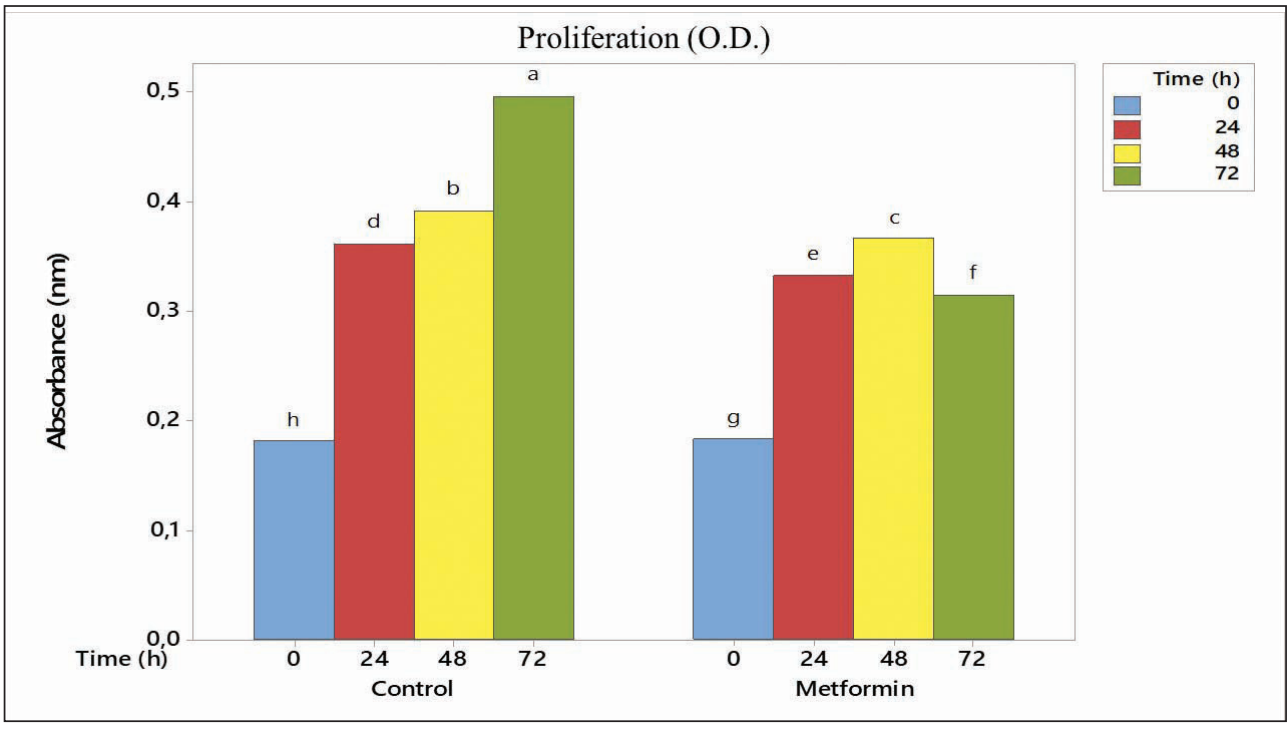

Figure 2: Graphical demonstration of MTT analysis. Cell proliferation suppressed in the metformin threated cultures, especially after 72 hours.

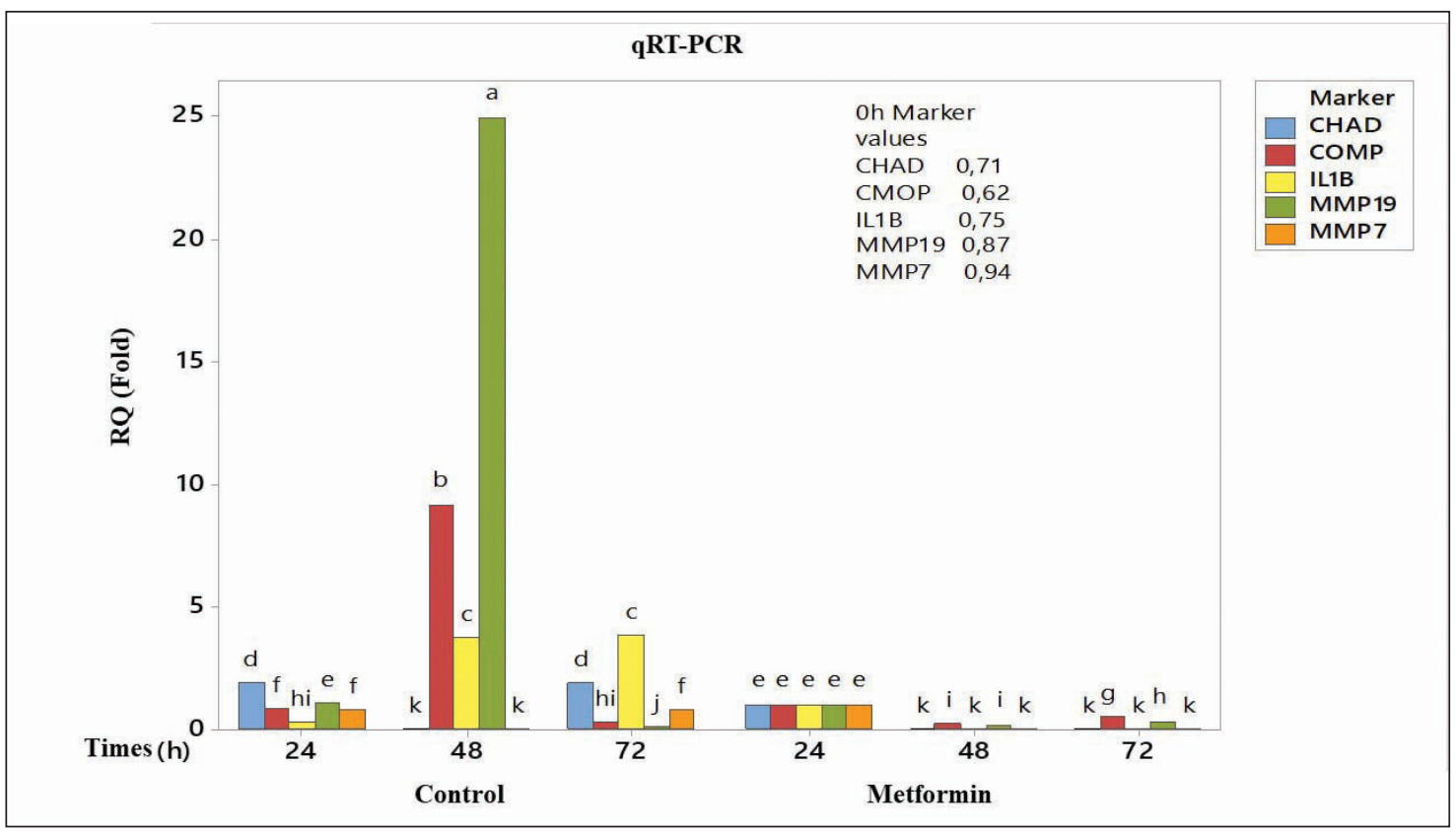

Figure 3: Graphical demonstration of qRT-PCR analysis of CHAD, COMP, IL1b, MMP7, and MMP19 genes. Obvious changes in expression profile were observed in cultures treated with metformin. 
baseline values of MMP-7 and MMP-19 expressions were 0.94-fold and 0.87-fold, respectively. No MMP-7 expression was observed at $72 \mathrm{~h}$. MMP-19 expression decreased 0.34fold in the metformin-treated group.

\section{DISCUSSION}

The absence of lymphatic vessels in human intervertebral disk tissues can cause a significant increase in the destruction of matrix-related structures. Many drugs, whether given orally or parenterally, are also known to accumulate in many tissues in the body, including the synovial fluid compartments (14-18). Drugs and nutrients can diffuse from hyaluronan and synovial tissues into body fluids. Later, they can pass through pores in the hyaline membranes located in the intervertebral disk space to reach the disk tissues (14-18). Metformin, isolated from the plant Galega officinalis, is an oral antihyperglycemic drug that has been used to treat type 2 diabetes mellitus since 1957 (26).

Metformin activates AMPK in the liver and muscles, suppresses gluconeogenesis in the liver, and has peripheral effects. Metformin is known to increase the level of glucagonlike peptide-1 (27), and slightly decrease insulin levels, which helps to lose weight. Consequently, metformin is also used by nondiabetic individuals to lose weight.

Metformin decelerates NP cell aging and apoptosis, increases the expression of anabolic genes (such as type II collagen and ACAN), and decreases the expression of catabolic genes (such as MMP-3 and ADAMTS-5) $(3,19)$. Studies on the effects of metformin to prevent, decelerate, and reverse disk degeneration have recently gained popularity. Furthermore, metformin has been reported to suppress cell proliferation, apoptosis, and autophagy by inducing the mTOR pathway $(19,22)$. In addition, although there is a significant correlation between Modic changes and severe diabetes mellitus, the correlation between diabetes mellitus and intervertebral disc degeneration is not clear (8).

The following results, which are in line with the literature, were extracted from the present study: a) the round-shaped cells that show the existence of cytotoxicity were observed in the metformin-treated group and b) cell proliferation was suppressed, and the extracellular matrix structures were disrupted in the metformin-treated group.

CHAD, an NP-specific marker, and COMP, an extracellular matrix protein also known as thrombospondin-5, play significant roles in the treatment of disk degeneration. The expression level of IL-1 $\beta$, a proinflammatory cytokine, and the expression levels of MMP-7 and MMP-19 are involved in the catabolic mechanism and are important. CHAD also plays a significant role in the regulation of chondrocyte growth and proliferation $(10,20)$.

The COMP gene encodes COMP found in the extracellular matrix of the cells that make up ligaments and tendons and the surrounding cartilage-forming cells. COMP plays a role in cell growth and proliferation, as well as in the regulation of cell movement and attachment. It may also be involved in the pathogenesis of osteoarthritis and may serve as a potent suppressor of apoptosis in primary chondrocytes, intervertebral disk cells, and transformed cells. IL-1 $\beta$ is a proinflammatory cytokine that induces prostaglandin synthesis; neutrophil influx and activation; T-cell activation and cytokine production; B-cell activation and antibody production; and fibroblast proliferation and collagen production in the extracellular matrix. MMP-7 and MMP-19 are members of the MMP family, consisting of structurally related zinc-dependent endopeptidases. The primary role of the activated MMP is to break down the extracellular matrix by degrading macromolecules like casein, gelatin, fibronectin, and proteoglycan (20).

In the present study, the suppression of proliferation and changes in gene expressions were monitored using a qRTPCR test. The expressions of CHAD, COMP, IL-1B, MMP-7, and MMP-19 continued in the control group, whereas those in the metformin-treated group changed significantly or no expression was observed.

CHAD expression (baseline value: 0.71-fold) remained unchanged in the control group. It ceased as from $48 \mathrm{~h}$ and was eliminated at $72 \mathrm{~h}$ in the metformin-treated group. COMP expression (baseline value: 0.62-fold) increased 9.17-fold at $48 \mathrm{~h}$ but decreased 0.29 -fold at $72 \mathrm{~h}$ in the control group. It decreased 0.52-fold following metformin treatment. IL-1b expression (baseline value: 0.75 -fold) increased 3.80 -fold at $72 \mathrm{~h}$ in the control group, whereas it decreased 1-fold at $24 \mathrm{~h}$ and was eliminated at $48 \mathrm{~h}$ after metformin treatment. Baseline values of MMP-7 and MMP-19 expressions were 0.94-fold and 0.87-fold, respectively. No MMP-7 expression was observed at 72 h. MMP-19 expression decreased $0.34-$ fold.

Studies performed recently have used either commercial cell lines $(5,28)$ or animal tissues (9). The commercial cell lines contain a single type cell and do not have their original phenotypic and genotypic characteristics. Therefore, the results of the experiments obtained using commercial cell lines may be misleading $(12-20,25)$. The literature also indicates that the sensitivity of human and animal tissues is different; accordingly, the results obtained in these studies may differ from the results obtained with human samples and may be misleading (13-18,25).

For these reasons, in the present study, the animal tissues or commercial cell lines were not used. Instead, the primary cell cultures were prepared from uninjured segment of disc material human intervertebral disk tissues. The effects of metformin were evaluated using the foregoing cell cultures. The results of the present study are believed to contribute significantly to the relevant literature. Although the findings obtained reveal that metformin negatively affected the cell cultures, it should be kept in mind that the present study was performed in an in vitro environment. Hence, the results may not accurately show the effects of metformin in clinical practice. This is the limitation of the study.

\section{CONCLUSION}

Metformin is commonly used in clinics for the treatment of 
type 2 diabetes mellitus due to the following effects: reducing hepatic glucose production by inhibiting, directly and indirectly, gluconeogenesis in the liver; improving insulin sensitivity by increasing the activities of kinase and GLUT-4; decreasing intestinal glucose absorption and increasing insulin sensitivity at the post-receptor level; significantly affecting adipose tissues when used as an antiobesity drug; and exerting hyperglycemic, antilipemic, and hepatoprotective effects. However, it should be kept in mind that metformin adversely affects cell cultures prepared from intervertebral disk tissues. Data obtained from six patients are not sufficient to provide an accurate conclusion. However, the present preliminary in vitro study provided significant data as it revealed that the drugs used may have effects on gene expression level. Further studies on different genes and signalling pathways are also needed.

\section{AVAILABILITY of DATA and MATERIALS}

The authors confirm that the data supporting the findings of this research are available within the article.

\section{REFERENCES}

1. Akgun FS, Sirin DY, Yilmaz I, Karaarslan N, Ozbek H, Simsek AT, Kaya YE, Kaplan N, Akyuva Y, Caliskan T, Ates O: Investigation of the effect of dipyrone on cells isolated from intervertebral disc tissue. Exp Ther Med 18:216-224, 2019

2. Bryrup T, Thomsen CW, Kern T, Allin KH, Brandslund I, Jørgensen NR, Vestergaard $H$, Hansen $T$, Hansen $T H$, Pedersen $\mathrm{O}$, Nielsen T: Metformin-induced changes of the gut microbiota in healthy young men: Results of a non-blinded, one-armed intervention study. Diabetologia 62:1024-1035, 2019

3. Chen D, Xia D, Pan Z, Xu D, Zhou Y, Wu Y, Cai N, Tang Q, Wang C, Yan M, Zhang JJ, Zhou K, Wang Q, Feng Y, Wang X, $\mathrm{Xu} \mathrm{H}$, Zhang $X$, Tian N: Metformin protects against apoptosis and senescence in nucleus pulposus cells and ameliorates disc degeneration in vivo. Cell Death Dis 7:e2441, 2016

4. Chen S, Zhou J, Xi M, Jia Y, Wong Y, Zhao J, Ding L, Zhang J, Wen A: Pharmacogenetic variation and metformin response. Curr Drug Metab 14:1070-1082, 2013

5. Correia-Branco A, Keating E, Martel F: Involvement of mTOR, JNK and PI3K in the negative effect of ethanol and metformin on the human first-trimester extravillous trophoblast HTR-8/ SVneo cell line. Eur J Pharmacol 833:16-24, 2018

6. Dujic T, Zhou K, Yee SW, van Leeuwen N, de Keyser CE, Javorský $M$, et al: Variants in pharmacokinetic transporters and glycemic response to metformin: A metgen metaanalysis. Clin Pharmacol Ther 101:763-772, 2017

7. Eksi MS, Kara M, Ozcan-Eksi EE, Aytar MH, Gungor A, Ozgen $\mathrm{S}$, Pamir MN: Is diabetes mellitus a risk factor for modic changes?: A novel model to understand the association between intervertebral disc degeneration and end-plate changes. J Orthop Sci 2019 (Epub ahead of print)

8. Espinoza SE, Jiwani R, Wang J, Wang CP: Review of interventions for the frailty syndrome and the role of metformin as a potential pharmacologic agent for frailty prevention. Clin Ther 41(3):376-386, 2019
9. Gabryel B, Liber S: Metformin limits apoptosis in primary rat cortical astrocytes subjected to oxygen and glucose deprivation. Folia Neuropathol 56:328-336, 2018

10. Geerling JJ, Boon MR, van der Zon GC, van den Berg SA, van den Hoek AM, Lombès M, Princen HM, Havekes LM, Rensen PC, Guigas B: Metformin lowers plasma triglycerides by promoting VLDL-triglyceride clearance by brown adipose tissue in mice. Diabetes 63:880-891, 2014

11. Hema Shree K, Ramani P, Sherlin H, Sukumaran G, Jeyaraj G, Don KR, Santhanam A, Ramasubramanian A, Sundar R: Saliva as a diagnostic tool in oral squamous cell carcinoma a systematic review with meta analysis. Pathol Oncol Res 25: 447-453, 2019

12. Kaplan N, Yilmaz I, Karaarslan N, Kaya YE, Sirin DY, Ozbek H: Does nimodipine, a selective calcium channel blocker, impair chondrocyte proliferation or damage extracellular matrix structures. Curr Pharm Biotechnol 20:517-524, 2019

13. Karaarslan N, Batmaz AG, Yilmaz I, Ozbek H, Caliskan T, Yasar Sirin D, Kaplan N, Oznam K, Ates O: Effect of naproxen on proliferation and differentiation of primary cell cultures isolated from human cartilage tissue. Exp Ther Med 16:16471654, 2018

14. Karaarslan N, Yilmaz I, Ozbek H, Sirin DY, Kaplan N, Akyuva Y, Gonultas A, Ates O: Are specific gene expressions of extracellular matrix and nucleus pulposus affected by primary cell cultures prepared from intact or degenerative intervertebral disc tissues? Turk Neurosurg 29:43-52, 2019

15. Karaarslan N, Yilmaz I, Ozbek H, Yasar Sirin D, Kaplan N, Caliskan T, Ozdemir C, Akyuva Y, Ates O: Are radio-contrast agents commonly used in discography toxic to the intact intervertebral disc tissue cells? Basic Clin Pharmacol Toxicol 124:181-189, 2019

16. Karaarslan N, Yilmaz I, Sirin DY, Baykiz D, Demirkiran A, Ates O: Do we damage nucleus pulposus tissue while treating cerebrovascular ischemic neurological deficits with nimodipine? Ann Med Res 25:266-273, 2018

17. Karaarslan N, Yilmaz I, Sirin DY, Ozbek H, Kaplan N, Kaya YE, Akyuva Y, Gurbuz MS, Oznam K, Ates O: Pregabalin treatment for neuropathic pain may damage intervertebral disc tissue. Exp Ther Med 16:1259-1265, 2018

18. Karaarslan N, Yilmaz I, Sirin DY, Ozbek H, Kaya YE, Akyuva Y, Kaplan N, Dogan M, Gumustas SA, Ates O, Erdem I: Does transcription factor, induced by daptomycin and vancomycin, affect HIF-1a, Chondroadherin, and COL2A1? Ann Med Res 25:756-762, 2018

19. Kaya YE: Systematic evaluation of the effects of metformin on the mTOR signalling pathway in the treatment of spinal cord injury. Merit Res J Med Med Sci 7:8-12, 2019

20. Kaya YE, Karaarslan N, Sirin DY, Ozbek H, Kaplan N, Yilmaz I: Investigation of the effects of methylphenidate, an amphetamine derivative, on intervertebral disc tissue cell cultures and matrix structures. Turk Neurosurg 29(5):734-742, 2019

21. Li YY, Stewart DA, Ye XM, Yin LH, Pathmasiri WW, McRitchie SL, Fennell TR, Cheung HY, Sumner SJ: A metabolomics approach to investigate kukoamine B-A potent natural product with anti-diabetic properties. Front Pharmacol 9:1575, 2019 
22. Ma WQ, Sun XJ, Wang $Y$, Zhu $Y$, Han $X Q$, Liu NF: Restoring mitochondrial biogenesis with metformin attenuates $\beta$-GPinduced phenotypic transformation of VSMCs into an osteogenic phenotype via inhibition of PDK4/oxidative stressmediated apoptosis. Mol Cell Endocrinol 479:39-53, 2019

23. Mears SC, Lipsett PA, Brager MD, Riley LH 3rd: Metforminassociated lactic acidosis after elective cervical spine fusion: A case report. Spine (Phila Pa 1976) 27:482-484, 2002

24. Piskovatska V, Strilbytska O, Koliada A, Vaiserman A, Lushchak O: Health benefits of anti-aging drugs. Subcell Biochem 91:339-392, 2019

25. Sirin DY, Kaplan N, Yilmaz I, Karaarslan N, Ozbek H, Akyuva Y, Kaya YE, Oznam K, Akkaya N, Guler O, Akkaya S, Mahirogullari $\mathrm{M}$ : The association between different molecular weights of hyaluronic acid and CHAD, HIF-1a, COL2A1 expression in chondrocyte cultures. Exp Ther Med 15:4205-4212, 2018

26. Ursini F, Russo E, Pellino G, D'Angelo S, Chiaravalloti A, De Sarro G, Manfredini R, De Giorgio R: Metformin and autoimmunity: A "New Deal" of an old drug. Front Immunol 9: 1236, 2018
27. Wu T, Thazhath SS, Bound MJ, Jones KL, Horowitz M, Rayner CK: Mechanism of increase in plasma intact GLP-1 by metformin in type 2 diabetes: Stimulation of GLP-1 secretion or reduction in plasma DPP-4 activity? Diabetes Res Clin Pract 106:3-6, 2014

28. Yakisich JS, Azad N, Kaushik V, lyer AKV: The biguanides metformin and buformin in combination with 2-Deoxy-glucose or WZB-117 inhibit the viability of highly resistant human lung cancer cells. Stem Cells Int 2019:6254269, 2019

29. Yang S, Dai Y, Liu Z, Wang C, Meng Q, Huo X, Sun H, Ma X, Peng J, Liu K: Involvement of organic cation transporter 2 in the metformin-associated increased lactate levels caused by contrast-induced nephropathy. Biomed Pharmacother 106: 1760-1766, 2018

30. Yong C, Dan L, Chenhong L, Yan S, Jianfei C, Jianlong G: Efficacy and safety of metformin for Behcet's disease and its effect on Treg/Th17 balance: A single-blinded, before-after study. Nan Fang Yi Ke Da Xue Xue Bao 39:127-133, 2019 